\title{
Smart City Planning
}

\section{Complexity}

Ekman, Ulrik

Published in:

International Journal of E-Planning Research

DOI:

10.4018/IJEPR.2018070101

Publication date:

2018

\section{Document version}

Publisher's PDF, also known as Version of record

Citation for published version (APA):

Ekman, U. (2018). Smart City Planning: Complexity. International Journal of E-Planning Research, 7(3), 1-21. [1]. https://doi.org/10.4018/IJEPR.2018070101 


\title{
Smart City Planning: Complexity
}

Ulrik Ekman, Department of Arts and Cultural Studies, University of Copenhagen, Roedovre, Denmark

\begin{abstract}
This article reflects on the challenges for urban planning posed by the emergence of smart cities in network societies. In particular, it reflects on reductionist tendencies in existing smart city planning. Here the concern is with the implications of prior reductions of complexity which have been undertaken by placing primacy in planning on information technology, economical profit, and top-down political government. Rather than pointing urban planning towards a different ordering of these reductions, this article argues in favor of approaches to smart city planning via complexity theory. Specifically, this article argues in favor of approaching smart city plans holistically as topologies of organized complexity. Here, smart city planning is seen as a theory and practice engaging with a complex adaptive urban system which continuously operates on its potential. The actualizations in the face of contingency of such potential are what might have the city evolve over time, its organization, its wholeness, and its continued existence being at stake from moment to moment.
\end{abstract}

\section{KEYWORDS}

Complexity, Holism, Reductionism, Smart City, Topology, Urban Planning

\section{INTRODUCTION}

This paper aims to address and alleviate the current lack of explicit and agreed-upon definitions of the terms 'smart city' and 'smart city planning' by discussing their implicit meanings in both existing research and number of concrete urban projects during the last 25 years. In particular, this paper will analyze and evaluate the three main tendencies at play in the adoption of reductivist approaches to 'smart city planning.' These concern the three key reductions of complexity made operational when singular priority and privilege are granted to strategic national politics (as in South Korean U-city projects), to advances in the third wave of information technology (as in the four major smart city projects in Japan, urban projects in the European Union, and the Cyberjava project in Malaysia), or to a new ICT-cognitive corporate business logic (as in the IBM project for "Smarter Cities" and the "Smart + Connected Communities" initiative by Cisco System Inc.). As an alternative to these as well as to any reductivism that simply reorders primary objectives, the last part of this article discusses and argues in favor of a holist approach to planning smart cities with complexity.

Both the notion and the theory of 'urban planning' call for complexification today. They are in need of different and more explicitly complex discursive negotiation and theorization. The vastly 
increased and often hyperbolic usage in research as well as broad public mediations during the last dozen years of the terms 'smart city' and 'smart city planning' bear witness to this. Both terms remain underdeveloped and underdetermined, but they nonetheless obviously call for something 'smarter' and more complicated than existing notions and approaches.

During the last quarter of a century it has become obvious to large segments of entire populations that urbanization is massively on the rise in global culture and presents a vast set of unresolved issues, both existential and research-specific. It has also become evident, at the very least to academics, that research and practical developmental work still in the main draw on modern and late modern notions of the city and urban planning even though these have become problematic or insufficient due to the new challenges that have emerged after 1945 and especially after the mid-1990s. The latter challenges emerge especially from the rise of globalization, late capitalism, neoliberalism, and network societies which are today well into their second major phase of development. The pressures of these new challenges are visible in the prominence granted in the urban planning of 1990s to globalization and the virtual reality of e-planning. They are then also visible in the tempered revision of this prominence in the early 2000s as the import of physical territory, the nation state, and the local returns, along with a different pursuit of mixed urban realities. ${ }^{1}$

Towards the end of the second decade of the 2000s, 'smart cities' have become a discursive signpost, a theoretical urgency symptomatic of the challenges faced by contemporary urban planning. One could say that 'smart urban planning' and 'smart cities' have become key stand-ins, in the history of the present, for the latency of urbanisms and cities to come. With respect to smart cities and their planning one would expect little return to talking about them as an exercise in ingenious design and architecture. It appears too simple to think of them as an applied art with certain functional requirements to be integrated, in the way that town planning could still be approached in Europe as late as 1945-1960 - although key insights from this modern tradition are still considered today, mostly on the local and tactical scales (Van Assche, Beunen, Duineveld, \& de Jong, 2013). It is much more to the point to recognize in the current underarticulation of 'smart city planning' a call for a 'smartness' that has to engage with a contemporary situation in which systems and rational process views of planning have both already been hegemonic for a period and have seen a set of upheavals from postmodern planning initiatives. ${ }^{2}$

As such stand-ins for the latency of urbanisms to come they are thus very important anomalies. 'Smart urban planning' and 'smart cities' might best be approached as future attractors, points of bifurcation in the present, or potential crystalline topoi from which important new city-developments are likely to emerge and become actualized. As such topoi, they have begun to attract a significant part of the attention lavished on the issues raised by the global expansion and intensification of urbanization and urban planning in late modernity. They have become key places from which results are expected. One looks to 'smart city planning' and 'smart cities' for answers to key issues of the wider late modern urban planning context, not least in the Western hemisphere. One begins to see them as what will deliver on the efforts during the last three decades to generate an intelligent urban planning.

It is by no means certain that 'intelligent' or 'smart' can here be taken to mean a late modern system planning, an approach to city and environment as a system of interrelated activities in constant movement, e.g., with the focus on social and economic acts found in David Harvey's work from the 1970s (Harvey, 1973). Likewise, it is unclear whether 'smart cities' are generally to be seen as a 'live' system functionality. But perhaps both this and the processual emphasis in rational planning can still be considered 'smart' (over and above original blueprint and teleological end-state approaches). It is also not certain that 'smart city planning' can be read as if it means continued subscription to the idea that rigorous 'scientific' analytic methods are needed, as in systematic empirical investigations and in the rational planning process of decision-making. Perhaps, though, 'smart' still means to be able to plan and control complex, dynamical systems of the urban and the environmental. 
Moreover, it is less than clear that 'smart planning' involves a continuation of one or more of the main critical showdowns with the rational and systemic planning paradigms, not least as regards comprehensive top-down planning with very little citizen involvement. Does 'smart planning' involve some kind and some degree of incrementalism (Lindblom, 1959), some parts of mixed scanning models (Etzioni, 1968), or something like participatory planning? Does it include some of the approaches developed under the headings of advocacy planning (Davidoff, 1965), transactive planning (Friedmann, 1973), and/or communicative planning (Lane, 2005)? Given the discursive and theoretical underdetermination of 'smart planning', these are difficult questions to answer. Perhaps, however, 'smart' is likely to include a broad and ethico-politically inclusive (and therefore hyperdifferentiated and difficult) discussion of citizens' and planners' value judgments concerning the city and the environment.

Doubt also persists as regards the upshot of postmodernism for 'smart planning,' beyond the debate over architectural style and aesthetic preferences not conforming to modern functionalism. It is not immediately clear whether or not 'smart city planning' entails a showdown with comprehensive planning thoroughly guided by Enlightenment reason, modern science and technology. It is unlikely that radical tout court rejections of rationality are considered 'smart' for contemporary planning. Nonetheless, it is an open question whether, and then how, 'smart planning' is led by current challenges towards questioning and abandoning the values and norms that guided the actualization of a solid part of modern urbanisms (e.g., functionality, simplicity, order, homogeneity, uniformity). Similarly, it remains a question whether and then how 'smart planning' will engage with the heritage of postmodernist pursuits of alternatives to one, universal, imperialist rationality, if the modern project is neither entirely abandoned nor just subjected to minor revision. Perhaps 'smart planning' is likely to include consideration of both a differentiation of urban rationalities and an engagement with complexity that may or may not be reducible via modern science and technology.

If the discursive and theoretical meaning is quite elusive, it is perhaps a little clearer what the key issues and the problems to be solved are in order for cities and planning to earn the epithet 'smart.' One today begins to expect cities and a mode of planning that would be 'smart' qua more capable of handling the relation of country and city, citizen influx and social segregation, by fleshing out a workable politics for polycentric national-regional urban synergies. One starts to hail smart city plans as the promise of solutions to most pressing and urgent urban concerns: technological efficiency; attentive and secure political governance in a more cosmopolitical epoch; economical profitability and competitiveness under global pressures; a hyperdifferentiated socius with a sense of community; a good or improved quality of cultural life; manageable migration in the face of overpopulation; an engagement with environment and urban territory that counters climate change and maintains sustainability in a strong sense.

Even though this list of expectations is heuristic and preparatory, it should be enough to suggest both the more or less utopian and hopeful tone of much current 'smart city' discourse and the fact that the task set out for 'smart city planning' is very difficult and complicated, to say the least. Both things lead one to ask for a better, more explicit definition of the term and the theory, and to ask for a more concrete account of actual planning initiatives and smart cities, if any such exist.

\section{'SMART’ CITIES AND CITY PLANNING}

Since no broadly agreed-upon definitions of the new terms 'smart city' and 'smart city planning' exist, just as 'smartness' remains in need of articulation, it is quite remarkable to encounter numerous plans and actual city developments. One might marvel at the risk involved in the projects undertaken just as one wonders what theoretical notions and planning methodologies guided them. Actual smart city projects are found, for instance, in Amsterdam, Barcelona, Milton Keynes, Singapore, Songdo, Stockholm, and Tel Aviv. It is perhaps less surprising to see the slightly delayed arrival of a great many research publications accompanying such developments. Research publications concerning smart 
cities generally are the more numerous whereas sources concerning the planning of these are much fewer. Both types of sources appear in the immediate wake of a considerable body of relatively recent scholarship addressing 'electronic communities,' (Graham \& Marvin, 1996) 'the wired city,' (Dutton, Blumler, \& Kraemer, 1987; Mitchell, 1995) 'the digital city,' (Aurigi, 2005) and 'the intelligent city' (Droege, 1990; Komninos, 2002; Mitchell, 2007). They tend in particular to testify to the challenges posed to existing notions of the city and planning by their coupling with societies co-evolving with ongoing inventions of networked information technology. In spite of the many interesting studies, the continued and currently still unresolved debates concerning the definition of 'smart city' and 'smart city planning' indicate that existing projects and research have not yet delivered an adequate empirical and theoretical armature to meet the kinds of plans and city developments deemed necessary.

Once one takes a closer look at existing smart city projects and the research published, however, it is possible to see the consequences of leaving unaddressed both the polysemia of 'smart city planning' and the assumptions behind the variants of positive hyperbole accompanying existing actualizations of smart city projects. These kinds of underarticulation have not delivered a sufficient negotiation for new notions and a new approach to planning. Rather, they have paved the way for a more or less unquestioned acceptance of notions of the 'smart city' and approaches to planning that not only remain implicit but also have turned out to involve reductionisms whose undesirable shortcomings have now begun to show. It seems less than 'smart' to silently accept that the 'smartness' of the city and its planning is not articulate and articulated.

Before inquiring further into one or more alternative approaches, it might be a good idea to circumvent repetition of the same by learning from the key kinds of reductionism that have been somewhat silently operative in the last two or three decades. One may identify at least three main kinds of reductionism in planning (political, technological, and economic). They operate differently but share a demonstrative lack of potential to generate and maintain a desirable and sustainable "smart 'urban evolution of a more complex type.

\section{Key Reductions in Existing 'Smart' Plans and Cities}

In one of the most simplifying moves, the question of smart cities and their planning is reduced in ethico-political fashion by turning it into one strict oppositional issue: for or against, good or bad. Both de facto city developments and existing research are in several instances marked by a gradual, tendential movement towards encounters with open conflict, a freezing into binary oppositions. As diagnosed critically by Kitchin as well as Marvin et al., a set of simplifications lead towards decisive evaluative accounts that are either in favor or against smart cities, either strongly highlighting the promises or forcefully articulating the pitfalls (Kitchin, 2016; Marvin, Ayala-Luque, \& McFarlane, 2016). In addition, there is a similar but more obviously politicized tendency towards establishing an opposition between smart urbanism and citizens' right to the city. An obvious and important example of this reduction via strong oppositions is the split between the very comprehensive, strategically top-down steered national political program for more than a dozen U-cities under way in South Korea from the mid-1990s onward and the main concerns in such a recent anthology as Citizens' Right to the Digital City (Foth, Brynskov, \& Ojala, 2016). This tendency is not least interesting because it affords a first glimpse of the problems generated by one kind of reductionism characteristic of existing plans and the first set of actual smart city developments. It begins to hint at possible critical engagements with the kinds of political and ethical privileging and prioritization that were adopted to keep at bay the complexity at stake.

When a movement such as citizens' right to the smart city emerges, it signals a return of a set of problems fairly well-known already from the operations of comprehensive planning and earlier top-down systemic and rational planning paradigms. It signals that too little was learnt from all the efforts in late modernity directed towards incrementalism, mixed scanning, advocacy as well as communicative and transactive planning approaches. Such a movement signals a broadly felt need to place a certain emphasis upon a progressive ethical approach to citizens' rights, on a participatory 
democratic governance inclusive of differences, as well as an emphasis on the import for current urban transformations of the social and cultural dimensions of citizens' lives. Not least, the re-emergence of such a movement demonstrates that these were key urban issues especially underprivileged and treated very reductively in that first wave of smart city developments of which South Korean U-cities are quite exemplary. ${ }^{3}$

This makes it considerably easier to pinpoint the kind of clear and hierarchical ordering of priorities that have so far been adopted as a reductionist move, with strategic national politics first, followed by information technological development and economics. In other words, the example of South Korea makes clear that in the first round of planning and actual developments the complexity of developing 'smart cities' was reduced by implicitly defining 'smartness' as the politically controlled deployment of the currently most advanced information and communication technologies as the key infrastructural determinants of a city formation. This was guided by a belief or assumption that such an approach would drive economic growth. That strategic political control, technological determinism, and overdetermination by quantifiable economic growth are primary concerns in the development of U-cities, to the detriment of a flatter ethico-political urban governance, urban cultural development, the social and individual quality of city life, and a sustainable engagement with the environment, is also acknowledged and made evident already in the first set of research efforts made by scholars close to the actual planning and city projects (C. T. Kim \& Kim, 2012; T. J. Kim, 2008; Shin, 2009). Moreover, Germaine Halegoua has made the interesting observation that here national politics have all along been significantly guided by the idea of an urban planning experiment generating an exemplary prototype of the U-city which would be native to South Korea, incorporate massive foreign investment, and later be a profitable export model (Halegoua, 2011).

This kind of vast reduction of the complexity at stake has already shown itself unable to deliver and maintain a 'smart city' and a 'smart city planning.' It is already subject to critique and revision internal to the South Korean program, notably by associated researchers. It is already subject to external critiques made by an international body of scholarship. In fact, contributors to both the earlier debates concerning the meaning and the actual development of the 'intelligent city' and the slightly later debates concerning the 'smart city' have presented accounts that problematize this kind of approach and the blind spots left by its mode of reductionism (Allwinkle \& Cruickshank, 2011; Aurigi, 2006; Böhlen \& Frei, 2010; Graham, 2004; Hollands, 2008). One might well consider the outcome of the South Korean project a first, strong argument in favor of a different approach to the complexity of the 'smart city.' Perhaps another kind of more complex, more holist, and more continuist planning approach is what is called forth here.

A second key reductionism adopted, which grants a strong, overdetermining privilege to technology, is probably the better known because the technological component has been very important in all the existing 'smart cities' as well as all the research, even as early as the initial treatments of the wired city. 'Smart cities' and 'smart city planning' are a little more recent in development, so they are not so much concerned with the initial rise of network societies. Rather, they immediately become empirically and theoretically tightly linked with the emergence of the third wave of information technology, after the mainframe computer and the personal computer. 'Smart cities' are thus conceived along with the development well after the mid-1990s of urban planning, urban design, and architecture in the expanded field. This happens in tandem with the unfolding of the second major phase of network societies which draw increasingly on out-of-the-box computing as well as the sociocultural and experiential horizon of a virtually and physically mobile citizenry. ${ }^{4}$

Consequently, 'smart cities' are not least theorized and planned guided by the assumption that 'smart' means to have urban computing move on from existing primarily as distinctly recognizable units so as to be multiplicitously and pervasively integrated into our living and working environments. Perhaps computing is to be altogether invisibly embedded in our life world and form of life. 'Smart cities' are then urban formations with 'ubiquitous computing' qua a technical and socio-cultural thrust to integrate and/or embed computing pervasively. 'Smart' means to have information processing 
thoroughly integrated with or embedded into everyday objects and activities, including those pertaining to human bodies and their bodily parts. Thus, for urban citizens to live with ubiquitous computing does not concern, or only marginally and momentarily concerns, engaging consciously with a single device or application for some definite purpose. Rather, it concerns engaging with multiple computational devices and systems simultaneously during more or less ordinary activities, without necessarily being aware of doing so. Urban models and practical implementations of ubiquitous computing largely adhere to something like Mark Weiser's vision. This vision concerned a myriad of small, inexpensive, robust, networked information processing devices. Perhaps these are mobile but they are certainly distributed at all scales throughout everyday life and culture, most often turned towards distinctly mundane, commonsensical, and commonplace ends.

Empirically speaking, this technological vision is in large part the guiding assumption behind the first phase of development of 'smart cities.' It is what leads towards an urban formation including an entire host of systems, often drawing upon networks of environmental sensors and actuators. Such networks control weather, floods, land movements, pollution, and noise. They include systems for dynamic collection and processing of waste as well as smart grids and meters for energy production and usage. They involve intelligent traffic control and transport systems, systems and central control rooms for coordinated emergency response, surveillance, and predictive policing. They also introduce city operating and management systems along with e-government systems and citizen information services, infrastructurally integrated building management systems, smart homes with a variety of app-controlled appliances.

The ghost of urban technological determinism haunts most visibly in the new 'smart cities' built from the ground up with advanced ICT infrastructures, as in South Korea, but the tendency is the same in the majority of projects aimed at innovative renewal of existing cities, e.g., in the four major smart city projects in Japan: Yokohama, Toyota City, Keihanna Eco-City, and Kitakyushu Smart Community Creation. It evidently needs to be repeated that granting primary and determining import to being dynamically and digitally connected is reductionist in a problematic way. Most frequently, if not always, it leads to undesirable urban formations. As the case of Mitaka in Japan shows, along with other pervasive urban healthcare projects across the world, being digitally connected does not necessarily lead to improvement of the quality of the lives of elderly inhabitants of the city, especially not in terms of improved social, human contact. As the largely missing cultural and social life in Songdo in South Korea hints, 'smart' technical connectivity and a high degree of 'augmentation' do not in and off themselves mean the generation of more, or even enough, social or cultural capital. It could also mean that people do not wish to live there, for example. As demonstrated in several heavily funded and technologically oriented 'smart' city projects in South-East Asia and the European Union, an autonomous sociocultural, economic, and environmental sustainability is the main bottleneck (Dameri \& Rosenthal-Sabroux, 2014). Without the funding, the citizens disappear along with the services and knowledge generated, leaving a dead city shell, an economic loss, and an environmental problem. Perhaps the utopian, boosterist Cyberjava project in Malaysia from the mid-90s, replete with science parks, technology districts, green areas for high-tech companies and housing for their employees, is one of the clearest examples of this. Within a decade, this project died out and was left a somewhat disconnected business park clone, having shown limited innovative capacity for a knowledge economy, very little in terms of benefits for a wider economic, social, and experiental development (Brooker, 2012).

The third key kind of reduction derives from granting an exaggerated, decisive privilege in planning to the ancient, even originary, operation of the city as a marketplace, a passage for monetary transactions, a hub for economic flows. In a sense, this is a tendency that continues from the kind of planning associated with the slightly earlier 'intelligent cities,' in Europe and the United States for example, which were in a great many cases driven by an anxiety as regards meeting the demands of the globalized market. Neither 'intelligent' nor 'smart' are subjected to any more extended analysis and discussion here. Instead it tends to be more implicitly understood that 'intelligent' or 'smart' means 
that the city should be planned and developed according to a new kind of business logic supported by current advances in information technology.

In the recent initiatives concerning 'smart cities,' this has led to very comprehensive, even totalizing, kinds of corporate urban planning and development. IBM's project for "Smarter Cities" thus encompasses technical systems for government and administration, city planning and operations, public safety, buildings, energy, water, transportation, education, healthcare, and social programs (IBM, 2017). The relative weightings among these are not made clear, but the intelligent reader will be able to identify a neoliberal discourse concerning unhindered urban evolutionary progress, which is anchored by the primary privilege granted to an improved urban business environment. On closer scrutiny, it seems that this "improvement" originates in the capacity of "the most advanced technologies" (qua "cognitive computing") to generate and operate upon "[t]he data that drives the smarter city" and presumably enables "[n]ew business models [that] target the creation of radical new efficiencies for long-standing challenges." In other words, 'smarter cities' are 'smart' because they are planned, developed, and maintained by a corporate governmentality. This is allegedly a quite neutral epistemological matter of "cognitive government," but further reading shows it to be primarily determined by the development of an economy based on big data, or, as the statements on the web site have it: a concern for "[e]nabling the data-driven economy in the cognitive era."

The same kind of leaning towards a reductive economic determinism is operative in the largescale initiative by Cisco System Incorporated entitled "Smart + Connected Communities" (Cisco Systems, 2017). The Cisco project includes technical urban systems for public services, operations centers, safety, lighting, traffic, parking, and waste management, and more. Cisco claims that its project has driven growth, e.g., it has had Kansas City foster "innovation and entrepreneurship through digital transformation." It has allegedly refreshed services, e.g., by having Barcelona use "cuttingedge solutions to address urban challenges like parking, lighting, traffic, and waste management." Presumably, it has generated an improvement of residents' quality of life, e.g., in Adelaide where government and state have partnered with Cisco to "digitally transform the city." As in the IBM case, the "Smart + Connected Communities" initiative hinges on the primary privilege granted to an information-based business logic for urban planning.

The Cisco project announces this already in its subtitle, stating that smart and connected urban communities are 'smart' because they first generate profit and then/therefore see to their citizens: "Create new revenue and better serve your citizens with smart city innovations." Although Cisco places more focus on the current development of the Internet of Things (IoT), the big data corporate business logic is essentially the same as for IBM. It rests on the assumption that investment in comprehensive urban IoT infrastructure "makes smart living possible and profitable." According to Cisco, their kind of initiative means that smart cities could see a profit of 2.3 trillion US dollars through 2024 via cost savings, efficiencies, and revenue generation. This would entail developments of a next-generation digitally connected work force, smart city utilities and metering, safety and security systems, connected systems for transport, mobility, and parking, systems for city infrastructure management, enhanced information systems for citizens, intensified broadband networking and increased generation of open big data.

Although it is a shared and taken for granted assumption in these large-scale initiatives, one would like to point out that digitalization does not equal value, i.e., that there is no necessary and linear determination starting with big digital data generation in the city and leading to monetary profit for the city. As several earlier 'intelligent' or 'smart' urban projects have demonstrated in practice, a host of other important variables are at stake, just as any economic profitability remains subject to considerably more uncertainty than this and often does not stay with the city involved. Furthermore, as both existing 'smart' city projects and parts of research have shown, the reductionism silently at work is not only unduly simplifying. It is neither the only approach nor necessarily the best one in terms of figuring out urban 'smartness' and 'intelligence.' 
Even if the deep problems of artificial intelligence lurking in the promise of cognitive, contextaware, and predictive human-oriented computing were likely to be solved (something still to be shown today), and even if this were translatable into a new profitable business logic (which also remains to be shown), then this does not in and off itself provide the grounds for a valuable and sustainable city. For example, this approach foreshortens an urban planning by not considering more in depth what a valuable city might mean, besides the generation of monetary values (e.g., environmental as well as existential sociocultural values). Already in the mid-90s, research began to point out that global economic anxieties and hopes were what blinded such urban plannings to critical reflection (Castells, 1996; Graham \& Marvin, 1996, 2001). Among other things, as several other publications also observe (Al Waer, 2012; Allwinkle \& Cruickshank, 2011), the reduction of 'intelligence' and 'smartness' to matters of information technical business logic has meant that urban planning projects did not begin to entertain the hypothesis that informative social and cultural capital, including quite complex dynamics of communicational and mediatory relations and exchanges, are quite pivotal and sometimes the more constitutive dimensions of the urban 'intelligence' and 'smartness' at stake. It is quite thought-provoking that not even insights from the massive rise of social and mobile media during the last two decades have been sufficient to dispel or thoroughly problematize this kind of corporate techno-economic reductionism.

\section{THE CALL FOR ALTERNATIVE KINDS OF PLANNING}

The three key kinds of reduction perceptible in the first wave of 'smart city' developments should, broadly and ideally speaking, lead to a growing realization that an alternative kind of urban planning is called for. The gradual increase in ethico-political disagreements, increased uncertainty as to economical profitability, and increasing individual, social, and cultural dissatisfaction could be said to showcase a set of urban developments undertaken based on undue reductions of complexity. These reductions have certainly begun to make felt their internal tensions and the implications of their tendential blind spots, exclusions, or uneven weighting of the major functional variables at play in the generation of a 'smart city.'

Nonetheless, the most obvious risk and the most likely outcome is still repetition of the same. That is, it still seems most likely that a next generation of 'smart cities' would tend to be planned in ways that might lead to revisions but ones that intensify the existing approaches. This would mean something like a second-order overdetermination by technological control via big data mining, another order of finely segmentalized and personalized marketing strategies and tactics for economic profit, and political decisions made in distributed but clearly hierarchically weighted networks. Long-term concerns such as climate, ecological sustainability, and overpopulation are most likely to be planning parameters or variables still granted rather low values.

However, if one wonders how another kind of 'smart city planning' is to emerge, one might well begin by asking what initiatives in urban planning would make for differences that make a difference, as Bateson would have said (Bateson, 2000). If approached somewhat specifically a second wave of smart city planning would make a difference by departing in some respects from the residues of national oligarchy found in South Korea whose top-down planning has demonstrated little in terms of equity, bottom-up hearings, or inclusion of the opinions and values expressed by citizens. In other words, it would make a difference to pursue as an alternative a more complex evolutionary approach to smart city co-governance. This would be one in which citizens are not only included formally as inhabitants, nor just engage with given governmental issues. Rather, citizens are rather continuously engaging in participant production of governance alongside existing institutions and their officials. This concerns mutually generative participation by citizens and institutions in an urban democracy: both are not only heard but have mutually constitutive and deconstitutive influence. Citizens' situations and those of city government bodies would thus co-develop in a contextually sensitive fashion. ${ }^{5}$ 
Secondly, planning would make a difference by departing in at least some respects from the kinds of overdetermination by corporate rule whose planning privileges attempts to structure the city according to profitable schemes and processes not just for commodity consumption but also for citizens' everyday experiences and bodily practices. Thirdly, planning would make a difference by deviating from technocracy and technological determinism. That is, it would make a difference to depart from a type of planning that tends towards implementing a third wave of urban computing as an infrastructure whose virtual and real environmental 'augmentations' move towards coding, recoding, and overcoding social and individual affectivity. This concerns a critical reflection upon and departure from the coding of everything from movements, through events and situations to encounters and sensations. It would make a difference to find alternatives in planning to implementing increasingly fine-grained systems with regulatory effects in the social public sphere in general and in terms of personalized and privatizing systems with behavioral effects on individual citizens. Very likely, alternative approaches for a 'smart' urban planning would here especially concern a different re-privileging of the potentials for urban community, sociality, and individual urban cultures.

To point towards such differences that would make a difference is already to remark that the strong polysemy of 'smart city' and 'smart city planning' as terms seems to resist a systematic simplification to a basic definition. The terms remain with more than one sense - definitions are very often referring circularly to 'smart,' 'smartness', and 'intelligence,' and the plural meanings are often in internal conflict, if more or less unacknowledged. The overt appearance of the conflictual tensions in current research and planning thus has the advantage of bringing to the fore some of the ideologies and values at stake in ascribing meaning to 'smart.' This may permit a certain explicitation of existing goals and definitions of key terms that have often been left implicit, but it certainly also may make room for the insight that alternatives exist. All of this should help make clear that the definition of 'smart city planning' is currently very much an issue still to be discussed, an issue demanding more and more explicit negotiation of tensions and conflicts among alternative meanings and values. As hinted at above, it is already an advance to point explicitly to alternatives - simply because these become explicit. In order to move towards one or more alternative notions of planning, it would probably help to formulate at least something like a preparatory, ideal typological account of the defining goals which are to enter the process of planning. Such an account might well include at least the list below.

The smart city is to be a city of movements and flows, a city of smart mobility in the sense that it includes intelligent inter-operable transport systems with dynamic routing and real-time information for citizens. Not unlike the modern and late modern city, the smart city is to be a territorialization, but this concerns the unfolding of a smart coupling of both physically and virtually real territories. The smart city is also to be a generator of smart urban environments which distinguish themselves from the milieu but do so by relating to materials, energy, and waste in ways that promote resilience and create sustainability. Hence cities would be 'smart' insofar as they maintain a co-development of territorializing technics and unfolding milieux, seeing to the membranes between these two and sustainable transports through them in both directions. Not entirely unlike earlier cities, the smart city is to be a polis, but one that fosters new modes of operational government, not least via more transparent, participatory, and accountable e-government. The smart city retains the role of an economical hub of commerce but is to do so by fostering smart entrepreneurship, innovation, productive competitiveness, and internal investment. As in earlier urban formations, the smart city is to be a social community and a cultural arena. Cities would be 'smart' insofar as they maintain and develop the quality of the social and individual urban life forms and the experiences of its inhabitants and visitors. Here smart cities are to produce smart, well-informed people and a culture of inclusion, creativity, participation, and empowerment. Smart cities are to improve the quality of life qua reducing risks, increasing safety, utilities, and services, and offering a greater freedom of choice. Last but not least, the smart city is to involve more or less neutral technical planning and urban problem solving that maximizes control, reduces cost, improves services, and supports a better quality of life. 
Considering this list, which is not comprehensive, it rapidly becomes clear that a new 'smart city planning' cannot make do with a reordering of primary privileges, as if it were 'smart,' for example, to grant the city as community determining primacy rather than the city as polis, as marketplace, or as territory in relation to an environment or milieu. It would seem obvious both that all parts of the list must be included and that the relations and weightings among them are not a matter of granting any one singular primacy. In fact, the complexity of the planning called for should be evident, and the internal tensions among the desired goals are likely to make themselves felt at once.

For example, the call for resilience and sustainability will right away enter into conflict with the call for the growth and profitability of an urban consumer society. The pursuit of a greater freedom of choice for individuals and social groups will right away run up against the call for technical control and reduction of risks. In a more contestatory vein, most if not all these partial definitions and somewhat idealized goals for planning have been or are likely to be subjected to critique. The relatively early work of Crang, Graham, and Hollands already indicated this. The later works of Adam Greenfield, Rob Kitchin, and Anthony Townsend also bear this out (Greenfield, 2013; Kitchin, 2014; Townsend, 2013).

Notably, projects for smart mobility may well elide ethico-political questions concerning who has physical and/or informational access to what parts of the city. Efforts towards smart territorialization often tend towards an abstract, global, and general delimitation from the milieux at stake, parenthesizing concrete, local specificities - their sites and their histories. Pursuits of allegedly resilient and sustainable smart cities most often are not sustainable in a more radical sense but include a few token green sub-projects, behind which corporatization and privatization of city services operate to appropriate urban functions as profitable opportunities in a market of consumption. The e-governments of smart cities frequently bracket movements towards equality, justice, deliberative democracy, and a participant citizenry by favoring top-down hierarchical governance, by seeing to the investments of vested interests, by extending technologies of surveillance and profiling, and by intensifying a fine-grained social and behavioral regulation. Aiming at making smart cities profitable economical hubs have sometimes proven a catastrophe leaving behind dead and abandoned city projects, at other times it has been considerably less profitable than imagined, and almost always the public good suffers just as more funds leave the city than circle into internal investment. Perhaps more than anything else, the social, communal, and cultural dimensions of the smart city often remain blind spots, are underdeveloped add-ons taken into account very late, or they simply remain reflections of the values of the main stakeholders.

Instead of seeing cause for despair in the encounter with such tensions and problems, and instead of seeking a simple solution by reordering among primary objectives, I propose to pursue 'smart city planning' as a theoretical and practical processual approach that is heuristically complex, holist, and continuist. In other words, even though this is difficult and still not an altogether mature and fully developed approach in urban planning, I would argue in favor of a planning with complexity.

\section{PLANNING WITH COMPLEXITY}

To suggest engaging in planning with complexity in this sense is almost certainly to ask for trouble and resistance. The science of complexity is a young discipline and hardly agreed upon. Moreover, planning with complexity amounts to saying that nobody already knows how to get it done theoretically, methodologically, and practically. For such 'smart city planning' can no longer assume a plan, sketch, diagram, or blueprint as an original ground or arche that will decide a city formation. Nor can it assume a teleological mode planning; i.e., that 'smart city planning' serves a meaningful human purpose by having an environment and a city, its functions, structures, and modes of urban life proceed towards a certain aim. Since it can also not assume the workability of a finite, discrete plan or diagram, it will have to assume that planning remains an infinitely finite process, one continuously engaging with contingencies. Among other things, this means that the emergence or arrival of a 
definite urban plan, a concrete urban design, an architecture of buildings with well-delimited forms permitting of measure and metric, as well as a specifiable form or urban life for citizens is a secondary side-effect. For 'smart urban planning' with complexity remains a matter of continuous formation and deformation in a more general topological sense. The planning of a smart city topos at stake is thus not a whole in the sense of a definite territory or place but concerns a holism in becoming. In such planning, the smart city is a complex placing and territorialization that is more than the sum of its parts. It is whole as a process of becoming, a process that engages with complexity so as to continue to maintain an emergent and creatively organizing structuration of a place and a population, if it is not torn apart or broken, if it does not dissipate or run into entropy.

Planning with complexity might be resisted because it entails a putting aside of traditional remainders of more static, objectifying, structural, blueprint and purposive approaches. More seriously, perhaps, it could be considered an uncomfortable project because its affirmation of holist emergence implies quite some discussion of any remaining predictive capacity for the discipline. In addition, the engagement with complexity and the problematization of reductivism could invite quite some refusals, insofar as this might mean a loss of the kind of inductive grounding that characterizes much of modern science in general. While there is no doubt that planning with complexity departs from much modern and late modern urban planning, this might not in and off itself be too worrisome insofar as this approach could turn out to present a considerably better and more realistic simulation of how 'smart city planning' operates. Then, approaches to both emergence and complexity come in a number of variants, only some of which imply loss in a strong sense of predictive capability and reduction whereas others restrict this as pertaining only to certain classes of systems. Here I am merely attempting to pave the way for more discussion of both terms and their usage in the field of urban planning. I do this here by pointing out that 'smart cities' often at least appear to be so complex that their behavior is new or emergent in the sense that it cannot be deduced from the properties of the urban elements or parts themselves. It is then an open discussion whether this must or should lead to adoption of a strong scientific holism approach. That is, the claim that 'smart cities' are and become in such a way that reductive models are in principle prohibited from finding an algorithm that can predict their behavior, no matter how much data is provided.

On a more affirmative note, one can observe that the suggestion to engage in planning with complexity is not unheard of. Urban planning has for quite some time been on its way to a fuller engagement with complexity in theory and practice. The impact on urban planning of general systems theory, second-order cybernetics, as well as theories of self-organization have paved much of the way for this from at least the 1970s onward (Bateson, 2000; Bertalanffy, 1968; Maturana \& Varela, 1980; Nicolis \& Prigogine, 1977; Von Foerster, 1995). Already in the mid-1980s the influence in urban planning was clear. Karen S. Christensen, for example, remarked then that planning is often fraught with uncertainty and calls for contingent approaches to complexity so as to discover order and organize means and goals (Christensen, 1985). ${ }^{6}$ The continued import of such lines of thought and practice has meant that one might claim that urban planning with complexity has come of age and is relatively more mature, seeing that more substantial work has now been undertaken (Batty, 2005; Healey, 2007; Healey, Hillier, \& Metzger, 2015; Juval Portugali, 2011; J. Portugali, Meyer, Stolk, \& Tan, 2012; Roo et al., 2012; Roo \& Silva, 2010).

On a second affirmative note: it is quite hard to deny that both the first and the coming wave of 'smart city planning' are necessarily complex, in which case urban planning would only be 'smart' if it can articulate the ways in which this is or becomes the case. The smart cities to be planned are matters of mobility and modes of movement for very large numbers of entities and bodies. They dynamically energize the processes and relations in environmental, technical, human sociocultural, political, and economic systems on small, medium, and large scales. They concern intense, ad hoc, and perhaps non-linear kinds of networking and (dis)connectivity. For example, the smart city calls for the planning and implementation of an artificial, dynamic, and intensely networked mixed reality (with a real and a virtual environment as well as an augmented virtuality and an augmented 
reality). ${ }^{7}$ In this mixed reality, the environment, the city, its transport systems, its cultures, the social body of its human inhabitants, its political system of governance, and its economic systems are all in co-development, not least with ubiquitous computing. The planning of this smart city mixed reality thus presupposes the diagramming of an exceedingly rich and complex interactivity among the multiplicities of nodes at play.

In view of this, there is quite some reason to assume that complexity as a key problem is always implied. For smart cities will in various ways demonstrate how complexity arises from a vast number of distinguishable relational regimes and their associated state spaces, promising a defined system of interactivity for a city to come. Only some of the nodes and their vertices in such a city are to be approached as physically territorial while others are virtual or augmented in various ways. Only some of them are partaking of the city in a relatively stable and static sense, whereas multitudes of others must be approached as in transformative movement. They are dynamically distributed, mobile, and highly variable in their modalities, times, and places of interactivity. For urban planning to be 'smart' would at least demand that it be capable of doing justice to the ways in which the 'smart city' demands diagramming of its multiplicities, their relational dynamics, as well as their potentially ongoing creative or dissipative character as a whole.

When setting out to engage in planning with complexity, a first productive move might well be made by seeing that the key challenge for smart cities mostly concerns their negotiations of the tensions between organized and disorganized complexity. That is, a first, more affirmative way to approximate a theoretical set of resources for dealing with complexity and emergence in this smart urban context can be found in a source as early as Warren Weaver's classic 1948 article on science and complexity (Weaver, 1948). This text might be said to present a forward step with its double distinction. It distinguishes first between 'problems of simplicity' (largely concerned with two variables) and 'problems of complexity.' It then distinguishes between problems of 'disorganized complexity' on the one hand (billions of variables as in physics and math, to be handled by probability theory and statistical mechanics), and, on the other, problems of 'organized complexity' (the middle region concerning ways to deal simultaneously with a sizable number of factors which are interrelated into an organic whole).

Perhaps Weaver can be particularly useful because these distinctions allow us to see that most questions concerning the complexity of smart urban planning belong to problems of 'organized complexity.' Reduction to simply two variable problems is not possible, but it is also most often not a matter of applying a mathematics of averages to a huge number of factors, although this does pertain to certain classes of smart urban systems. Not least, an approach via this middle kingdom of organized complexity might permit us to acknowledge holism and the occurrence of emergence, i.e., that which Weaver already pointed to when saying that members of diverse groups can work together to form a unit which is much greater than the mere sum of its parts (542). ${ }^{8}$

\section{CONCLUSION}

Once one goes on to consider whether smart urban planning with complexity tends towards organized or disorganized complexity, one is most likely to confront also the challenge posed by irreducible complexity. This would not be entirely unlike the kind of work on the complexity of cellular automata systems undertaken by Stephen Wolfram, for example (Wolfram, 1984, 1986, 2002). That is, as a planner one would very likely try to decide whether smart cities concern urban systems of such complexity that their surprising behaviors, perhaps arising from interconnectivities across multiple system levels, cannot be computed and cannot be predicted. At best, smart urban planning would here mean to try to approximate the urban system via a 1:1 simulation of its situations and events. I think this problem is likely to lead to a certain division into camps in urban planning, most practitioners shying away from the uncomfortable implications of engaging with urban planning as a matter of complexity in the strong sense. 
It appears very likely, I think, that planning with complexity would be considerably more appealing if it were more workable on the side of organized complexity and included some pragmatic version of reductionism. That is why a source such as Herbert Simon's work on the sciences of the artificial could very well come to function as a hinge for a number of engagements with planning with complexity (Simon, 1996). Simon's review of earlier $20^{\text {th }}$ Century debates in the sciences concerning holism and reductionism as approaches to complexity provides a useful background here due to its unapologetic pragmatism and Simon's own adherence to a version of reductionism. This work remains a useful entry and resource in a more extended discussion whether the complexity of smart city planning can be or should be approached via something like Simon's pragmatically oriented building of nearindependent theories for each successive level of complexity, while also building bridging theories which show how each higher level can be accounted for in terms of the elements and relations of the next level below. With this in mind, it should be possible to see additional debate as to whether one can or should adopt a pragmatic stance that:

- Defines a complex smart city system as one that is made up of a large number of parts that have many interactions and is weakly emergent in the sense that given the properties of the parts and the laws of their interaction it is not a trivial matter to infer the properties of the whole;

- Affirms that smart city complexity often takes the form of hierarchy in a broadly formalized sense (not necessarily with relations of authority (master/slave)), i.e., a system composed of interrelated subsystems each of which is in turn hierarchic in structure until we reach some lowest level of elementary subsystem (Simon, 183-185).

It could well be, however, that some interesting middle course would be the more interesting and productive to steer. That is, not to decide that irreducible urban complexity is the problem nor to decide that pragmatic urban system building with some parentheses around transversal movements is the problem. One might affirm that a great many kinds of smart city system effects may best be modeled or simulated as arising from complexity, in the form of a non-linear coming together and dispersal of diverse interactants and components. But one may approach this situated on the limit of urban capacity for organization of complexity, formally keeping the limit open onto disorganized complexity. Perhaps smart city system effects and events must remain a complexly moving target for planning, as points or as waves, but they can be seen to form such points and waves. Perhaps the complexity of smart city systems cannot be strictly defined, but they can, momentarily and locally, be placed as fluctuations somewhere between ordering of structures and dissipating into disorder (Nicolis \& Prigogine, 1977; Prigogine \& Stengers, 1984). This may be approaches on and as the limit of ordering and organizational structuration.

According to such a middle course in planning with complexity, smart city systems are unpredictable and uncontrollable but only to quite some degree. They are also positively emergent qua tendentially self-organizational. That is, they are artificially 'designing' qua letting local, momentary, and singular interactive dynamics eventually produce broader, more lasting, and more connective coordination and synergy. On this middle course, one can likewise investigate whether smart city systems are emergent in a strong and/or a weak sense. As a planner, one may explore, at the limit of urban organization, whether and how a spontaneous ordering of complex urban systems and patterns out of a multiplicity of relatively simple operations and interactions do and/or do not go beyond the qualities of their components.

When pursuing further such a middle course of planning with complexity, the work of Gilbert Simondon on relational ontogenesis can (and should) be seen as a very rich and valuable resource. It would enable an affirmation of a smart city plan as an organized complexity, or a flat, sizeable, and open multiplicitous whole of requirements in cross-cutting relational tensions. It would permit an interesting look at breaks or fault lines of the apparent equilibrium, the relative resolution, that smart cities and their planning has currently arrived at. It would permit an engagement with a smart 
city plan as a set of heterogeneous potentials for what can be done with a city, whether this means the actualization of some genuinely new organized structuration or rather the deterioration and disassemblage of a city project.

I would argue in favor of exploring smart city planning, with Simondon in mind, affirming such planning as concerned with urban potentials that are necessarily unresolved and in process. Current smart city planning is thus approached as a "metastable" situation to be entered into and affirmed. ${ }^{9}$ Smart cities and their planning concern a multiplicity of forces and elements in movement whose relationalities may (or may not) permit the actualization of another organized complexity. One would be planning smartly insofar as the smart city comes to operate as an ongoing individuation. ${ }^{10}$

I would consider 'smart urban plannings' as crystalline topoi where urban metastabilities can be tried to see whether they enter into other individuations in the form of new actualizations of cities as organized complexities. This amounts to arguing in favor of approaching smart city planning as a topological issue, an approach that concerns trying and testing a complex, holist, and continuist diagramming. This is highly likely to circumvent binary oppositions and too obviously inadequate reductionisms. It also might well lead to a realization of where the fault lines are - it might well provide indications of where and how continuous deformations of the smart city as an organized complexity meet with tears, breaks, or cuts. In other words, this is to propose to approach smart city planning as a theory and practice engaging with the processes of a complex, dynamic, and adaptive system whose actualizations has the city evolve or devolve over time, its organization, wholeness, and continuity remaining in question in a different way in each event. ${ }^{11}$

Reconsidered with the thought of Gilbert Simondon, smart city planning would be a matter of a relational ontogenesis that need not be Euclidean but may rather be a self-maintaining of topological conditions for an urban spacing that continuously relates a milieu of organized interiority to a milieu of exteriority, one of more or less entirely disorganized complexity. Insofar as the city is alive or lively, its ongoing planning can be said to maintain as technics a membrane that is polarized and asymmetrical, between the organizable and the more strictly disorganized. Urban technics will let pass some kinds of bodies in centripetal or centrifugal directions, but it will oppose other kinds of bodies. This is the way in which the urban maintains itself topologically, always re-polarizing itself asymmetrically via selectivity. It keeps an interior in relation to an exterior milieu by living at and on itself own limit of self-maintenance, more or less sustainable. The smart city is thus one example of a highly complex and adaptable urban organism with diverse levels of interiority and exteriority. The relational, ontogenetic structuration of the smart city is not solely a matter of integration and differentiation, but rather also a prior dynamic topology: the continuous transductive instauration of numerous mediations of interiorities and exteriorities (Simondon, 1964, pp. 222-266).

To pursue with Simondon such a middle, ontogenetically relational course in planning with complexity is not just a theoretical endeavor, but also a practical one. In fact, this course and its engagement with a multiplicity of individuating systems in potential and to some extent actualized co-evolution mimicks very precisely what is being proposed and pursued in certain parts of existing research and actual developments of smart city projects. To give but a single example in conclusion, it is highly interesting to see that current efforts concerning development of a new kind of mixed reality urban governance for smart cities work towards a politics of co-evolutionary individuation which includes encounters with disorganized and perhaps irreducible complexity. Encounters with the potentials lurking in disorganized complexity are key for the individuation of the next generation of smart city planning and governance. Such city planning and governance engage with the interactions among millions of citizens aware of their context and billions of ICT units which interrelate dynamically in context-aware systems. Reductionisms will have to come into play here, realistically and pragmatically speaking. Nonetheless, smart cities might well become safer, stronger, more profitable, more socially diverse and culturally whole, and more sustainable if planning and governance find new ways to integrate at least some of the many potentials not actualized when reductions to organized complexity are undertaken. Likewise, it might be a real asset to become 
aware of the kinds of reductionism adopted, since a memory and registration of this would permit both backtracking and future re-planning for a city, as well as crosscutting comparisons with the planning undertaken in other cities.

Taking on the challenge of disorganized complexity implies a much flatter and more ad hoc networked type of governance and planning than anything one can find in the first wave of plans and actual smart cities. It is extraordinarily interesting to see it affirmed and recognized in different ways in some of the most recent research and projects. First, one of the leading researchers co-responsible for further development of the u-cities in South Korea, Jong-Sung Hwang, points out that u-cities have proceeded past an e-governance 1.0 that functions well with ICT systems. U-cities are now also passing through a platform governance 2.0 that opens to citizens via web and apps. The goal is to move towards a smart government 3.0 that thinks and develops with the mesh of contextual data generated massively and continuously by systems and citizens (Hwang, 2013). Secondly, it is highly interesting to see a large and detailed anthology such as Human Smart Cities begin to point towards a politics of soft urban planning for the city 3.0 in which the collective imagination and intelligence of the citizens is harnessed in the making of the city, taking into account the full sensory experience and the emotional impact of the urban environment (Concilio, 2016).

Notably, entries in this anthology recognize the greater risk involved in the encounter with uncertainty and disorganized complexity but nonetheless advocates an approach via participatory, collaborative, and creative urban planning. It is also a refreshing and interesting supplement to the technologically oriented South Korean projects to see this anthology emphasize the human in smartness. It is noteworthy that this volume presents the politics of urban design and planning as a complex participatory process of transformation involving a civic intelligence in the environment, one in which all citizens exist as living urban laboratories. Not entirely different from certain systems theoretical approaches and some of Simondon's insights, this volume paves the way for encounters in governance with disorganized complexity by passing through notions of public-private-people partnerships and multiple coordinating systems towards an open investigation of boundary objects and trading zones that may permit coordinated interaction among very varied living labs, in spite of or perhaps precisely because of marked differences and disorganized separations. 


\section{REFERENCES}

Al Waer, H. (2012). From Intelligent to Smart Cities. London: Routledge.

Allwinkle, S., \& Cruickshank, P. (2011). Creating Smart-er Cities: An Overview. Journal of Urban Technology, 18(2), 1-16. doi:10.1080/10630732.2011.601103

Araya, D. (2015). Smart Cities as Democratic Ecologies. London: Palgrave Macmillan. doi:10.1057/9781137377203 Aurigi, A. (2005). Making the Digital City: The Early Shaping of Urban Internet Space. Aldershot, UK: Ashgate.

Aurigi, A. (2006). New Technologies, Same Dilemmas: Policy and Design Issues for the Augmented City. Journal of Urban Technology, 13(3), 5-28. doi:10.1080/10630730601145989

Aurigi, A., \& De Cindio, F. (2008). Augmented Urban Spaces: Articulating the Physical and Electronic City. Aldershot, UK: Ashgate.

Azuma, R. T. (1997). A Survey of Augmented Reality. Presence (Cambridge, Mass.), 6(4), 355-385. doi:10.1162/ pres.1997.6.4.355

Bateson, G. (2000). Steps to An Ecology of Mind. Chicago: University of Chicago Press.

Batty, M. (2005). Cities and complexity. Cambridge, MA: MIT Press.

Bedau, M., \& Humphreys, P. (2008). Emergence: contemporary readings in philosophy and science. Cambridge, MA: MIT Press. doi:10.7551/mitpress/9780262026215.001.0001

Bertalanffy, L. v. (1968). General system theory: foundations, development, applications. London: Allen Lane. London: Penguin.

Böhlen, M., \& Frei, H. (2010). Ambient Intelligence in the City. In H. Nakashima, H. K. Aghajan, \& J. C. Augusto (Eds.), Handbook of ambient intelligence and smart environments (pp. 911-938). New York: Springer. doi:10.1007/978-0-387-93808-0_34

Brooker, D. (2012). "Build it and they will come"? A critical examination of utopian planning practices and their socio-spatial impacts in Malaysia’s “intelligent city”. Asian Geographer, 29(1), 39-56. doi:10.1080/102 25706.2012.659192

Castells, M. (1996). The Rise of the Network Society. Cambridge, MA: Blackwell Publishers.

Christensen, K. S. (1985). Coping with uncertainty in planning. Journal of the American Planning Association, 51(1), 63-73. doi:10.1080/01944368508976801

Cisco Systems. (2017). Smart+Connected Communities. Retrieved 12.08., 2017, from https://www.cisco.com/c/ en/us/solutions/industries/smart-connected-communities.html?stickynav=1

Combes, M. (1999). Simondon individu et collectivité: pour une philosophie du transindividuel. Paris: Presses Universitaires de France.

Concilio, G. (2016). Human smart cities: Rethinking the interplay between design and planning. New York: Springer. doi:10.1007/978-3-319-33024-2

Concilio, G., \& Rizzo, F. (Eds.). (2016). Human smart cities: Rethinking the interplay between design and planning. New York: Springer. doi:10.1007/978-3-319-33024-2

Crang, M., \& Graham, S. (2007). Sentient cities: Ambient intelligence and the politics of urban space. Information Communication and Society, 10(6), 789-817. doi:10.1080/13691180701750991

Dameri, R. P., \& Rosenthal-Sabroux, C. (2014). Smart City: How to Create Public and Economic Value with High Technology in Urban Space. Cham: Springer International Publishing.

Davidoff, P. (1965). Advocacy and pluralism in planning. Journal of the American Institute of Planners, 31(4), 331-338. doi:10.1080/01944366508978187

Droege, P. (1990). The intelligent city: Southeast Asian city of the future? Cambridge, MA: MIT. 
Dutton, W. H., Blumler, J. G., \& Kraemer, K. L. (1987). Wired cities: Shaping the future of communications. Boston: G K Hall.

Ekman, U. (Ed.). (2013). Throughout: Art and culture emerging with ubiquitous computing. Cambridge, MA: MIT Press.

Ekman, U. (2015). Design as topology: U-City. In F. Marchese (Ed.), Media art and the urban environment (pp. 177-202). Cham: Springer International. doi:10.1007/978-3-319-15153-3_9

Ekman, U. (2016). Ubiquitous computing, complexity and culture. New York: Routledge.

Etzioni, A. (1968). The active society: a theory of societal and political processes. London: Collier-Macmillan.

Foth, M., Brynskov, M., \& Ojala, T. (Eds.). (2016). Citizens right to the digital city. Berlin: Springer.

Friedmann, J. (1973). Retracking America; a theory of transactive planning. Garden City, NY: Anchor Press.

Graham, S. (2004). The cybercities reader. London: Routledge.

Graham, S., \& Marvin, S. (1996). Telecommunications and the city: Electronic spaces, urban places. London: Routledge. doi:10.4324/9780203430453

Graham, S., \& Marvin, S. (2001). Splintering Urbanism: Networked infrastructures, technological mobilities and the urban condition. London: Routledge. doi:10.4324/9780203452202

Greenfield, A. (2013). Against the smart city. Do Projects.

Halegoua, G. (2011). The policy and export of ubiquitous place: investigating South Korean U-Cities. In M. Foth, L. Forlano, C. Satchell, \& M. Gibbs (Eds.), From social butterfly to engaged citizen (pp. 315-333). Cambridge, MA: MIT Press.

Hansen, M. B. N. (2006). Bodies in code: Interfaces with digital media. New York: Routledge.

Harvey, D. (1973). Social justice and the city. Baltimore, MD: Johns Hopkins University Press.

Healey, P. (2007). Urban complexity and spatial strategies: Towards a relational planning for our times (1st ed.). London: Routledge.

Healey, P., Hillier, J., \& Metzger, J. (2015). Connections: exploring contemporary planning theory and practice. Farnham: Ashgate.

Hollands, R. G. (2008). Will the real smart city please stand up? City, 12(3), 303-320. doi:10.1080/13604810802479126

Hwang, J.-S. (2013). Smart city and smart government: strategy, model, and cases of Korea. Retrieved from http://www.slideshare.net/hjs0199/smart-city-and-smart-government-strategy-model-and-cases-of-korea

IBM. (2017). IBM Smarter Cities. Retrieved 12.08.2017, from https://www.ibm.com/smarterplanet/us/en/ smarter_cities/overview/

Juarrero, A., \& Rubino, C. A. (2008). Emergence, complexity, and self-organization: precursors and prototypes. Goodyear, AZ: ISCE Pub.

Kim, C. T., \& Kim, M. S. (2012). Deduction of a U-City strategy by analyzing cases worldwide. Information, 15(2), 483-495.

Kim, T. J. (2008). Planning for knowledge cities in ubiquitous technology spaces. In Creative urban regions (pp. 218-230). Academic Press.

Kitchin, R. (2014). Making sense of smart cities: Addressing present shortcomings. Cambridge Journal of Regions, Economy and Society, 8(1), 131-136. doi:10.1093/cjres/rsu027

Kitchin, R. (2016). Reframing, reimagining and remaking smart cities. SocArXiv. Retrieved from Open Science Framework website: https://osf.io/cyjhg/

Komninos, N. (2002). Intelligent cities: Innovation, knowledge systems, and digital spaces. London: Routledge. 
Lane, M. (2005). Public Participation in Planning: An intellectual history. The Australian Geographer, 36(3), 283-299. doi:10.1080/00049180500325694

Lindblom, C. (1959). The science of 'muddling through'. Public Administration Review, 19(2), 79-88. doi:10.2307/973677

Marvin, S., Ayala-Luque, A., \& McFarlane, C. (Eds.). (2016). Smart urbanism. London: Routledge.

Maturana, H. R., \& Varela, F. J. (1980). Autopoiesis and cognition: The realization of the living. Dordrecht, The Netherlands: Academic Press.

McCullough, M. (2004). Digital ground: Architecture, pervasive computing, and environmental knowing. Cambridge, MA: MIT Press.

McCullough, M. (2013). Ambient commons: attention in the age of embodied information. Cambridge, MA: The MIT Press.

Milgram, P., \& Kishino, F. (1994). Taxonomy of mixed reality visual displays. IEICE Transactions on Information and Systems, E77-D(12), 1321-1329.

Mitchell, W. J. (1995). City of bits: space, place, and the infobahn. Cambridge, MA: MIT Press.

Mitchell, W. J. (2007). Intelligent City. Retrieved from http://www.uoc.edu/uocpapers/5/dt/eng/mitchell.pdf

Nicolis, G., \& Prigogine, I. (1977). Self-organization in nonequilibrium systems. New York: Wiley.

Portugali, J. (2011). Complexity, cognition and the city. Heidelberg, Germany: Springer. doi:10.1007/978-3642-19451-1

Portugali, J., Meyer, H., Stolk, E., \& Tan, E. (Eds.). (2012). Complexity theories of cities have come of age. Berlin: Springer. doi:10.1007/978-3-642-24544-2

Prigogine, I., \& Stengers, I. (1984). Order out of chaos (1st ed.). Boulder, CO: New Science Library.

Protevi, J. (2006). Deleuze, Guattari and Emergence. Paragraph, 29(2), 19-39. doi:10.3366/prg.2006.0018

Roo, G. d., Hillier, J., \& Wezemael, J. v. (2012). Complexity and planning: systems, assemblages and simulations. Burlington, VT: Ashgate.

Roo, G. d., \& Silva, E. A. (2010). A planner's encounter with complexity. Burlington, VT: Ashgate.

Rydin, Y., \& Tate, L. E. (2016). Actor networks of planning: exploring the influence of actor network theory. London: Routledge.

Sassen, S. (1997). The new centrality: the impact of telematics and globalization. In P. Droege (Ed.), Intelligent environments: spatial aspects of the information revolution (pp. 19-27). Amsterdam, New York: Elsevier. doi:10.1016/B978-044482332-8/50004-4

Sassen, S. (2003). Reading the city in a global digital age. In L. Krause \& P. Petro (Eds.), Global cities: cinema, architecture, and urbanism in a digital age (pp. 15-30). New Brunswick, NJ: Rutgers University Press.

Sassen, S. (2006). Territory, authority, rights: from medieval to global assemblages. Princeton, NJ: Princeton University Press.

Sassen, S. (2011). The impact of the new technologies and globalization on cities. In R. T. LeGates \& F. Stout (Eds.), The city reader (5th ed.; pp. 554-562). London: Routledge.

Shin, D. H. (2009). Ubiquitous city: Urban technologies, urban infrastructure and urban informatics. Journal of Information Science, 35(5), 515-526. doi:10.1177/0165551509100832

Simon, H. A. (1996). The sciences of the artificial (3rd ed.). Cambridge, MA: MIT Press.

Simondon, G. (1964). L'individu et sa genèse physico-biologique. Paris: Presses Universitaires de France.

Simondon, G. (1989). L'individuation psychique et collective. Paris: Aubier. 
Simondon, G. (1992). The genesis of the individual. In J. Crary \& S. Kwinter (Eds.), Incorporations (pp. 296-319). New York: Zone.

Taylor, N. (1998). Urban planning theory since 1945. London: SAGE.

Townsend, A. M. (2013). Smart cities: Big data, civic hackers, and the quest for a new utopia. New York: W.W. Norton \& Company.

Van Assche, K., Beunen, R., Duineveld, M., \& de Jong, H. (2013). Co-evolutions of planning and design: Risks and benefits of design perspectives in planning systems. Planning Theory, 12(2), 177-198. doi: $10.1177 / 1473095212456771$

Von Foerster, H. (1995). Cybernetics of cybernetics: Or control of control and the communication of communication (2nd ed.). Minneapolis, MN: Future Systems.

Wang, X., \& Schnabel, M. A. (Eds.). (2008). Mixed reality in architecture, design, and construction. New York: Springer.

Weaver, W. (1948). Science and Complexity. Scientific American, 36, 536-544. PMID:18882675

Weiser, M. (1991). The Computer for the 21st Century. Scientific American, 265(3), 94-104. doi:10.1038/ scientificamerican0991-94 PMID:1675486

Weiser, M., \& Brown, J. S. (1997). The coming age of calm technolgy. In J. D. Peter \& M. M. Robert (Eds.), Beyond calculation (pp. 75-85). Copernicus. doi:10.1007/978-1-4612-0685-9_6

Weiser, M., Gold, R., \& Brown, J. S. (1999). The Origins of Ubiquitous Computing Research at PARC in the Late 1980s. IBM Systems Journal, 38(4), 693-696. doi:10.1147/sj.384.0693

Wolfram, S. (1984). Cellular Automata as Models of Complexity. Nature, 311(5985), 419-424. doi: $10.1038 / 311419 \mathrm{a} 0$

Wolfram, S. (1986). Approaches to complexity engineering. Physica D. Nonlinear Phenomena, 2(1-3), 385-399. doi:10.1016/0167-2789(86)90309-X

Wolfram, S. (2002). A new kind of science. Champaign, IL: Wolfram Media.

\section{ENDNOTES}

1 This development can be traced in existing research in urban studies and urban planning in general, but it can also be highlighted within a single authorship. See the developments in a subset of Saskia Sassen's publications from the late 90s to the second decade of the 2000s (Sassen, 1997, 2003, 2006, 2011).

2 I am suggesting that it is today an open and pressing question to what extent and in what ways "smart planning' entails a departure from the status quo presented in such a broadly used textbook in urban planning as Nigel Taylor's (Taylor, 1998).

3 I consider the issue of the design and planning of the South Korean smart city of Songdo in much more detail elsewhere (Ekman, 2015).

4 I am referring broadly to the third wave of computing, after mainframes, after personal computing, and in tandem with the rise of mobile and social media technics. Specifically, I have in mind the developments in urban cultural contexts after Mark Weiser's early vision in the mid-90s for a calm human-oriented computing, (Weiser, 1991; Weiser \& Brown, 1997; Weiser, Gold, \& Brown, 1999) i.e., the developments during the last 20 years, notably in and around cities in South-East Asia, Europe, and the U.S., of ubiquitous computing, pervasive computing, ambient intelligence, and the Internet of Things. Interesting approaches to this technocultural development can be found in Crang and Graham (2007), Ekman (2013, 2016), and McCullough (2004, 2013).

5 I note in passing that the technological development of context-aware systems pave the way for somethng like this and that approaches akin to this are being considered, at least in recent research, if not yet so much in actual smart city developments (Araya, 2015; Concilio \& Rizzo, 2016).

$6 \quad$ Christensen's later work on planning is also interesting in that she suggests a relational approach to distinguishing among degrees of complexity in order to deal with a reality that confronts planners with uncertainty. See chapter three elsewhere (Roo, Hillier, \& Wezemael, 2012). 
$7 \quad$ I refer to 'mixed reality' and 'augmentation' as defined in the recognized and widely used sources from computer science and human-computer interaction (HCI) (Azuma, 1997; Milgram \& Kishino, 1994). I go into further detail with respect to competing notions elsewhere (Ekman, 2013, pp. 13-18, 44-49). A post-phenomenological approach to embodied experience in and of mixed reality can be found in the work undertaken by Mark B. Hansen (Hansen, 2006). The interested reader can find other treatments of mixed reality in the fields of architecture, design, and construction (Wang \& Schnabel, 2008) and in the field of augmented urban spaces (Aurigi \& De Cindio, 2008).

8 I generally use the term 'emergence' in the sense found in significant parts of philosophy, systems theory, natural science, and art. Here it denotes a process whereby larger entities, patterns, and regularities arise through interactions among smaller or simpler entities that themselves do not exhibit the properties of the whole. In that general sense, emergence is central to theories of complex systems. More specifically, I would point to the interesting notion of 'emergence' proposed by John Protevi in his work on Deleuze and complexity theory, including distinctions among synchronic, diachronic, and transversal emergence in homogeneous and heterogeneous variants (Protevi, 2006). Here 'emergence' is defined as the diachronic construction of functional structures in complex systems that achieve a synchronic focus of systematic behavior as they constrain the behavior of individual components. The debate concerning the ontological and/or the epistemic status of 'emergence' is unresolved and quite old at this point in time. Readers may get a first overview of classical and more recent positions by consulting some of the relevant sources (Bedau \& Humphreys, 2008; Juarrero \& Rubino, 2008).

$9 \quad$ Here 'metastability' is used in Gilbert Simondon's philosophical sense. It designates a situation that is far from equilibrium, one that has a higher magnitude of energy than a simply stable one. I use the term to signal that the planning of 'smart cities' today is a system that already has arrived in a state of partial, relative resolution, but also one that contains latent potentials, harbors incompatibilities with itself due to forces in tension as well as to the impossibility of interaction between terms of extremely disparate dimensions (Simondon, 1992, p. 300). I approach 'smart city' as a systemic process in metastable or false equilibrium, knowing that the least modification to the parameters is enough to break the equilibrium. The present article is to be considered such a getting into contact with heterogeneous potentials as will provoke another individuation of 'smart city' planning, another actualization as an organized complexity according to certain structures (see also Combes, 1999, p. 11).

'Individuation' is generally used in a broad sense as the name of the processes whereby the undifferentiated tends to become individual, or the processes through which differentiated components become integrated into stable, if momentary wholes. It can thus be taken to refer broadly to different generative or processual philosophical efforts, as in key parts of the work by Bergson, Whitehead, James, the late Husserl, Deleuze, Bernard Stiegler, and Manuel De Landa. More specifically, however, it is used here with reference to Gilbert Simondon's developments of theories of individual, collective, and technical individuation. The individual or the collective subject is considered as an effect of individuation rather than a cause. Thus, the individual atom is replaced by the never-ending ontogenetic process of individuation. Simondon also conceived of the pre-individual as the virtuality or reserve making actual individuation possible. Here individuation is an always incomplete process, always leaving a pre-individual leftover, affording future individuations (cf., Simondon, 1964, 1989).

11 My approach diverges from most of the main modern and late modern theories and practices in urban planning, e.g., the dismissal by (certain UK) practitioners of theory as well as approaches that emphasize the rational-comprehensive, incremental, transactive, or the communicative, or ones promoting advocacy, equity, radical and critical urbanist concerns. My approach diverges because I think that a processual and genetic approach must be granted more weight than earlier, and because smart city planning cannot but involve the contingency of a history of the present. This means, among other things, that an approach is called for that may begin to address a planning process that acknowledges complexity qua a multitude of variables and degrees of freedom. However, my approach shares key issues, assumptions, and insights with several recent efforts in dynamical systems theory, complexity science, and the extension of science and technology studies and actor-network theory into assemblage theories. At least within the last 5-10 years such approaches have begun to make quite an impact on urban planning theory and practices (Batty, 2005; J. Portugali et al., 2012; Roo et al., 2012; Roo \& Silva, 2010; Rydin \& Tate, 2016). 
Ulrik Ekman is Associate Professor at the Department of Arts and Cultural Studies, University of Copenhagen. Ekman's main research interests are in the fields of cybernetics and ICT, the network society, new media art, critical design and aesthetics, as well as recent cultural theory. He is currently the head of the Nordic research network "The Culture of Ubiquitous Information" with more than 150 participating researchers. Ekman is behind the publication of Ubiquitous Computing, Complexity and Culture (Routledge, 2015), a comprehensive anthology treating the question whether and how the development of network societies with a third wave of computing may have emerge another kind of technocultural complexity. He is also the editor of Throughout: Art and Culture Emerging with Ubiquitous Computing (MIT Press, 2013). Ekman's publications include research articles and chapters such as "Editorial: Interaction Designs for Ubicomp Cultures" Fibreculture 19, "Design as Topology: U-City," in Media Art and the Urban Environment (Springer 2015), "Of the Untouchability of Embodiment I: Rafael Lozano-Hemmer's Relational Architectures." C-Theory (2012), "Irreducible Vagueness: Augmented Worldmaking in Diller \& Scofidio's Blur Building." Postmodern Culture 19.2, and "Of Transductive Speed - Stiegler." Parallax 13.4. 